\title{
Determination of Different Structures' Materials Natural Frequencies using Fuzzy Logic System
}

\author{
Maha M. A. Lashin, Wafaa Shoukry Saleh, Fadwa Alrowais
}

\begin{abstract}
The impact of structure's material and dimensions on its natural frequency are lacking in recent literature. The main aim of that paper is investigating material' characteristics effect on structures natural frequency. Five different types of materials (steel, concrete,wood, plastic and aluminum) which mostly used in engineering applications implemented in this study. A fuzzy system designed and structured for each type of materials. It used to optimize the natural frequency values related to height and area of structure. The results show that whilst the height of the structure is a very influential factor on its natural frequency, the type of material as well as area of the structure are also effective variables. For the same dimensions of the structure, wood shows the highest value of natural frequency, then steel followed by concrete. In addition, the natural frequencies of structures have been assessed against the wind, earthquakes and traffic vibrations. These results can have useful applications and recommendations for engineering and design purposes. Wood can complement natural properties of a range of materials. Implications from this investigation can be useful for heavy machines laboratories, building structures and other engineering applications.
\end{abstract}

Keywords: Natural frequency, Structure material, Structure dimensions, Fuzzy logic control system

\section{INTRODUCTION}

The value of Natural frequencyis the frequency value that at which a system tends to vibrate in absence of driving or damping forces. The natural frequencies are characteristics of materials. Structures of different materials tend to oscillate at these frequencies with a motion pattern defined as the normal mode. The natural frequencies and vibration of structures have been investigated and reported in the literature [1]. Vibrations of structures depend on its mass and stiffness. In general, heavier structures are expected to be of smaller amountof natural frequencies than lighter structures[2]. One of the widely claimed and established factors that influence the stiffness of a building or structure is its height [3]. The resonant frequency is the frequency at which the oscillating system is driven at using some exogenous factors [4].

Revised Manuscript Received on February 05, 2020.

* Correspondence Author

Maha M. A. Lashin*, College of Engineering, Princess Nourah bint Abdulrahman University, Riyadh, KSA, Mechanical Engineering Department, Faculty of Engineering Shoubra, Banha University, Egypt. Email: mmlashin@pnu.edu.sa

Wafaa Shoukry Saleh, Visiting Professor, College of Engineering, Princess Nourah bint Abdulrahman University, Riyadh, KSA. Edinburgh Napier University, Scotland, UK. E-mail: w.saleh@napier.ac.uk

Fadwa Alrowais, Faculty of Computing and IT Princess, Department of Computer Science, Princess Nourah Bint Abdulrahaman University, Riyadh, KSA. E-mail: FMAIRowais@pnu.edu.sa

(C) The Authors. Published by Blue Eyes Intelligence Engineering and Sciences Publication (BEIESP). This is an open access article under the CC BY-NC-ND license (http://creativecommons.org/licenses/by-nc-nd/4.0/)
It is well acknowledged in the literature that shorter buildings tend to be less flexible, so they tend to have higher natural frequencies compared to taller buildings [5], [6]. There has been recognition in the literature that the height of a structure has the most impact on natural frequencies of buildings [7], [8].

Investigations of optimization design through high-rise buildings considering the reliability and comfortability of the inhabitantand joint distribution of the direction and speed of wind, but not the impacts of different types of materials, done in [9].

Impacts of external forces on buildings such as wind and damping have been investigated extensively in theliterature. [10] investigated the behaviour of six shapes of structures with turbulent wind. The study reported that the impacts of the wind on different structures are affected by the aerodynamics and directions. Characteristics of materials include stiffness, dampness and mass. The study employed some statistical and integration techniques to assess the performance. [11]using ambient vibration measurements to investigate modal mass to estimate civil buildings and damping ratios. [12]analysed analytically pile-supported bridges to predict natural frequencies.

[13] improving seismic performance of building that affected with earthquake by using base isolated buildings with tuned mass dampers. They tested the effectiveness of the design methodology using optimization procedures. They used their model to analyze and calculate structure' frequencies and mode shape. [14]used a laser speckle imaging and parallel computing to assess natural frequencies. Eigenvalues of each model order used to compute natural frequencies. They developed a parallel code including different algorithms with k-means clustering whichapplied each cluster geometrical centroid as a virtual sensor. The dynamic characteristics of tall structures evaluated by Bayesian approach which use vibration shake test tables, [15].

In this paper, we investigate the impacts of height, area, ratio of height/area, density and stiffness of structures on their natural frequencies. An analysis of structures' performance with variations of these parameters are performed using fuzzy logic control system. Fuzzy logic based on theory of fuzzy sets, [16].

Fuzzy logic which formed many-valued logics that implemented through concept of partial truth[17], [18]. It offers a useful approach to carryout conflict resolution of multiple criteria and an efficient method of analysis, comparison and evaluation.

Mathematical Calculation of Natural Frequency of structure that is stemming from the original natural frequency formula that presented in equation (1) as following: 


\section{Determination of Different Structures' Materials Natural Frequencies using Fuzzy Logic System}

$$
\omega_{n}=\sqrt{\frac{K}{M}}
$$

Where:

$\omega_{n}=$ natural frequency (rad./s.)

$\mathrm{K}=$ the structure stiffness

$\mathrm{M}=$ the structure mass

The structure's mass is an important factor in the analysis of its natural frequency (or how flexible structures are). It is well recognized that the direct and inverse relations between mass, structure' height respectively with natural frequency, higher structure have lower natural frequency, while shorter structure have higher natural frequency. Similarly, heavier structure has lower natural frequency. On the other hand, increasing structure flexible has also a good effect on its natural frequency, the lighter (or less mass) the structure is the greater its natural frequency and the heavier the structure (more mass) or more flexible (that is less stiff), the lower its natural frequency. The natural frequency-in Hertz therefore is given by $f_{n}$ below:

$f_{n}=\frac{1}{2 \pi} \omega_{n}$

From equations (1 and 2)

$f_{n}=\frac{1}{2 \pi} \sqrt{\frac{K}{M}}(3)$

$K_{\text {moment frame }}=2\left[\frac{12 E I}{\mathrm{H}^{3}}\right](4)$

Where

$\mathrm{E}=$ Young'smodulus of elasticity

$\mathrm{I}=$ Mass moment of inertia

$\mathrm{H}=$ Structure height

$M=\frac{V}{\rho}(5)$

Where

$\mathrm{V}=$ Volume

$\rho=$ Density

$V=M * \rho$

From equations (5 and 6)

$M \frac{A * H}{\rho}$

From equations (3, 4 and 7)

$f_{n}=(1.875)^{2} \sqrt{\frac{E * I}{A * \rho * H^{4}}}$

Equation (8) presents the vibration or the natural frequency for a structure as a function of the parameter's height, area and moment of inertia of the structure. In addition, the density and

modulus of elasticity of structure material also have impact on its natural frequency.

\section{NATURAL FREQUENCY OF STRUCTURES}

To study and analyze the performance of the vibration and the natural characteristics of structures, Five materials steel, concrete,wood, plastic and aluminum. Steel is composed of several components including iron, carbonand other components. Steel has high strength and not expensive. It has many uses in various types of structures, buildings and many light and heavy industries. Concrete is a composite material that also include several components. These are cement, sand, water and others. In many cases, concrete is used as reinforced. Concrete has many uses and applications in buildings purposes. Its usage worldwide is almost twice that of many materials combined including steel, wood, plastics and aluminum. Wood is a natural product that is available for most countries, yet its use is quite partial and limited to restricted applications[6].

Characteristics of the five materials are presented in Table I.The range of values for area, height, density and modulus of elasticity that are used to calculate the structure's natural frequency are presented in Table I.

Table- I: Natural characteristics of the five studied materials

\begin{tabular}{|c|c|c|c|c|}
\hline \multirow[b]{2}{*}{ Materials } & \multicolumn{4}{|c|}{ Natural characteristics } \\
\hline & $\begin{array}{l}\text { Density } \\
\left(\mathrm{Kg} / \mathrm{m}^{3}\right)\end{array}$ & $\begin{array}{l}\text { Modulus } \\
\text { of } \\
\text { Elasticity } \\
\text { (Psi) }\end{array}$ & $\begin{array}{c}\text { Height } \\
\text { (m) }\end{array}$ & $\begin{array}{c}\text { Width } \\
\text { (m) }\end{array}$ \\
\hline Steel & 7900 & $29 \times 10^{6}$ & $\begin{array}{l}10-100 \\
\text { (with a } \\
\text { "10" } \\
\text { step) }\end{array}$ & $\begin{array}{c}5-35 \\
(10- \\
100 \\
\text { (with a } \\
\text { "5" } \\
\text { step) }\end{array}$ \\
\hline Concrete & 2335 & $44 \times 10^{5}$ & $\begin{array}{l}10-100 \\
\text { (with a } \\
\text { "10" } \\
\text { step) }\end{array}$ & $\begin{array}{c}\text { 5-35 } \\
\text { (10- } \\
100 \\
\text { (with a } \\
\text { "5" } \\
\text { step) }\end{array}$ \\
\hline Wood & 750 & $136 \times 10^{5}$ & $\begin{array}{l}10-100 \\
\text { (with a } \\
\text { "10" } \\
\text { step) }\end{array}$ & $\begin{array}{c}5-35 \\
(10- \\
100 \\
\text { (with a } \\
\text { "5" } \\
\text { step)) }\end{array}$ \\
\hline Rubber & 1522 & $0.1 \mathrm{GPa}$ & $\begin{array}{l}\text { 10-100 } \\
\text { (with a } \\
\text { "10" } \\
\text { step) }\end{array}$ & $\begin{array}{c}5-35 \\
(10- \\
100 \\
\text { (with a } \\
\text { "5" } \\
\text { step) }\end{array}$ \\
\hline Aluminum & 2.71 & $69 \mathrm{GPa}$ & $\begin{array}{l}\text { 10-100 } \\
\text { (with a } \\
\text { "10" } \\
\text { step) }\end{array}$ & $\begin{array}{c}5-35 \\
(10- \\
100 \\
\text { (with a } \\
\text { "5" } \\
\text { step)) }\end{array}$ \\
\hline
\end{tabular}

The natural frequencies of structures have been investigated in relation to structure dimensions. All calculations are based on a model of a solid and homogeneous structure as seen in Fig. 1. Table II shows natural frequency values for selected dimensions of structures. If structure' height increases its natural frequency will decrease. while the structure' area increases its natural frequency also increases. Therefore, the ratio of height to area is of significance. Out of the five selected materials, wood show the highest natural frequency, across the entire range of areas, while aluminum shows the lowest natural frequency.

Published By: 


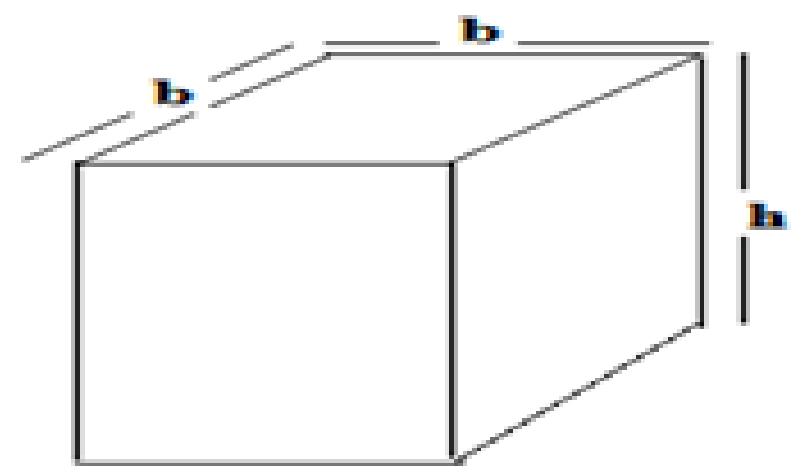

Fig. 1. Structure with square side (b) and Height (h)

Table - II: Natural frequency related to change in ratio of (height/area) of structures

\begin{tabular}{|c|c|c|c|c|c|}
\hline \multirow{2}{*}{$\begin{array}{c}\text { Ratio } \\
\text { (H/A) }\end{array}$} & \multicolumn{5}{|c|}{ Natural Frequency (Hz) } \\
\cline { 2 - 6 } & steel & concrete & wood & rubber & aluminum \\
\hline 0.01 & 21.5 & 8 & 30 & 0.0021 & 0.05 \\
\hline 0.1 & 2 & 1 & 13 & 0.0001 & 0.02 \\
\hline 0.3 & 3 & 2.5 & 8 & 0.00009 & 0.0005 \\
\hline 0.5 & 0.08 & 0.01 & 0.8 & 0.000003 & 0.00081 \\
\hline
\end{tabular}

\section{DETECTION OF STRUCTURE'S NATURAL} FREQUENCY USING FUZZY LOGIC CONTROL

Optimization techniques are increasingly used in many engineering applications [19], [20]. Fuzzy logic is a powerful optimization tool in dealing with complex problems. It designed for allowing determination of distinctions through data with simulating process of human reasoning [21] depending on computers. It defined as a nonlinear input data set mapping for scalar output data [21]. It based on fuzzifier, rules, inference engine, and defuzzifieras in below Figure 5 .

The process of fuzzy logic assumed here follows the approach adopted by Mendel [12].In summary the process involves obtaining set of input data that converted to fuzzy sets by membership functions (fuzzification). A set of rules are adopted then to make an inference. The fuzzy output used membership functions for defuzzification.

\section{FUZZY SYSTEM FOR NATURAL FREQUENCY}

Fuzzy logic system is used for optimization of the structure's natural frequency. Different structure dimensions presented to detect the maximum value of natural frequency for steel, concrete and wood materials. The MATLAB software used to build five fuzzy logic systems: one system for each material type. The system inputs were structure's properties (height, height/area) and structure materials specifications including density and modulus of elasticity. Outputs of fuzzy logic system are structure natural frequencies.

The fuzzification step in creation of fuzzy logic system appeared in Fig. 2 where fuzzy system has 2 inputs and 1 output. Fig.3 illustrates fuzzy system inputs membership functions. Fig. 4 presents the fuzzy system outputs membership functions for steel. Fig.5 shows the changing in natural frequency values that are related to changes in of height and height/area ratio for steel, concrete and wood respectively. Finally, Fig.6 shows the height and height/area ratio values at maximum natural frequency value of Steel Fuzzy System.

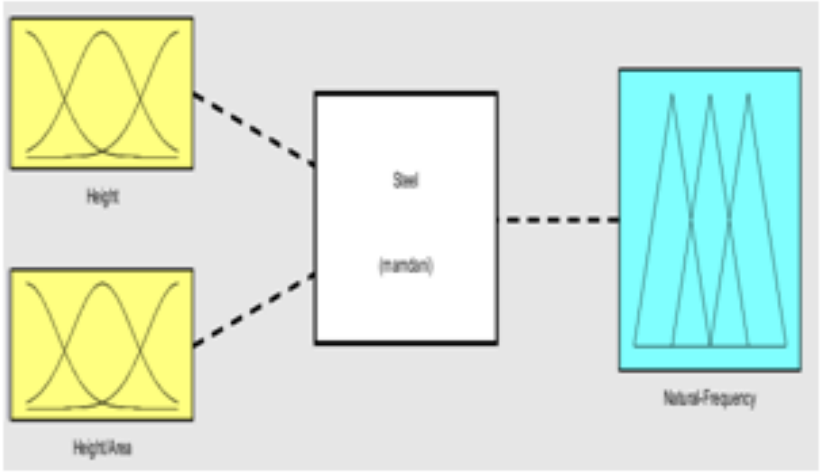

Fig.2. Fuzzy Logic System Architecture

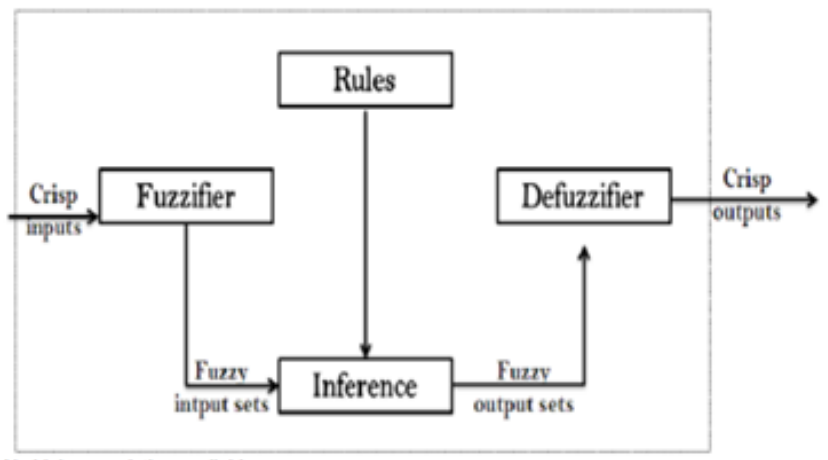

Fig. 3. Inputs and Output of fuzzy System (Steel)

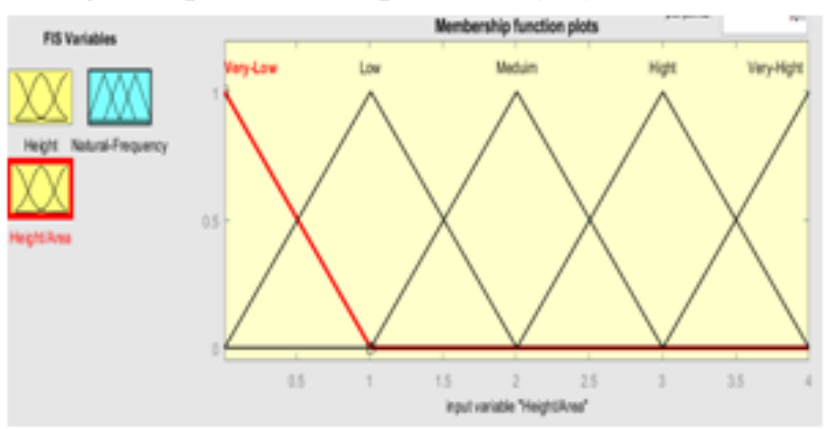

Fig.4: Inputs membership functions of fuzzy system (Steel)

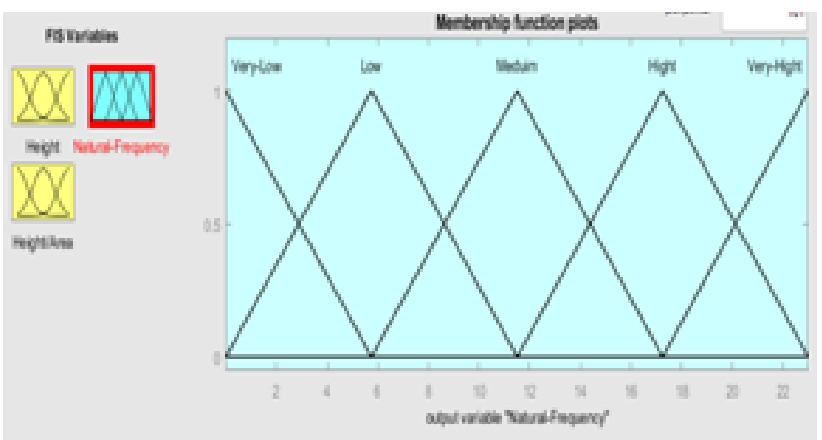

Fig. 5. Outputs membership functions of fuzzy system(Steel)

Published By:

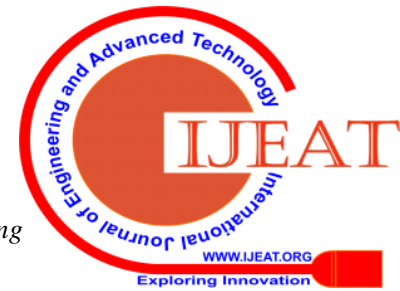




\section{Determination of Different Structures' Materials Natural Frequencies using Fuzzy Logic System}

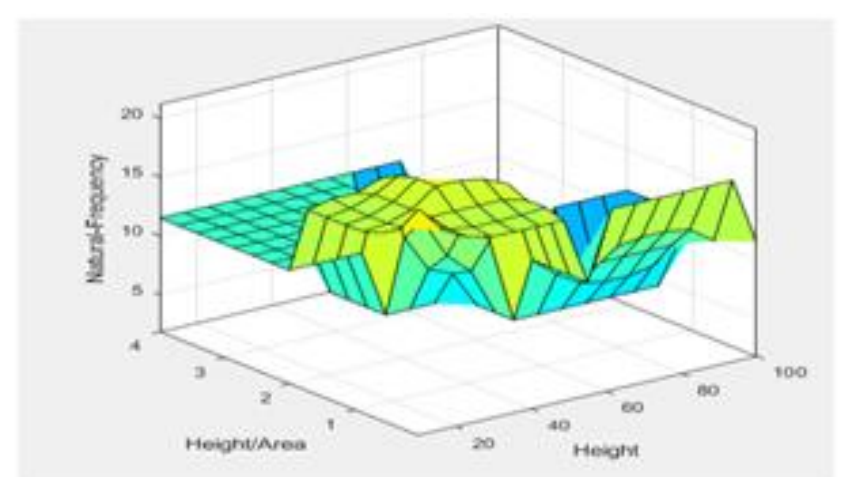

Fig.6. Representation of changing in natural frequency values related to changes of height and height/area ratio for steel fuzzy system

Table-IIIshows the results of optimization based on a cubic structure with three values of sides (10, 20 and 30 meters), a parallel rectangle shape of a structure with ratio (2:1) and a parallel rectangles structure with a ratio of height to base (3:1). Results confirm the results obtained from initial investigations. Maximum value of structure' natural frequency obtained when ratio of height to base equals to 1 . As the ratio of height to base increases the structure's natural frequency reduces. The results also confirm that wood has the highest natural frequency compared to other material investigated here (steel, concrete, rubber and aluminum). Further research in this area is recommended.

Table-III. Values of natural frequencies for the five materials within the experimental values

\begin{tabular}{|c|c|c|c|c|c|c|c|}
\hline $\begin{array}{l}\text { Ratio } \\
\text { (H:b) }\end{array}$ & \multirow{2}{*}{$\begin{array}{l}\text { H } \\
\text { (Hig } \\
\text { ht) } \\
\text { in } \mathbf{m}\end{array}$} & \multirow{2}{*}{$\begin{array}{l}\text { b } \\
\text { (sid } \\
\text { e) } \\
\text { in } \\
\text { m }\end{array}$} & & \multicolumn{4}{|c|}{$\begin{array}{l}\text { Natural Frequency of } \\
\text { Materials }\end{array}$} \\
\hline \multirow[t]{4}{*}{$\begin{array}{l}\text { Cubic } \\
(1: 1)\end{array}$} & & & $\begin{array}{l}\text { Ste } \\
\text { el }\end{array}$ & $\begin{array}{l}\text { Concr } \\
\text { ete }\end{array}$ & $\begin{array}{l}\text { Wo } \\
\text { od }\end{array}$ & $\begin{array}{l}\text { Rub } \\
\text { ber }\end{array}$ & $\begin{array}{l}\text { Alumin } \\
\text { um }\end{array}$ \\
\hline & 10 & 10 & 6.2 & 4.1 & 14.5 & $\begin{array}{c}0.000 \\
8\end{array}$ & 0.50 \\
\hline & 20 & 20 & 3.3 & 2.1 & 6.91 & $\begin{array}{c}0.000 \\
4\end{array}$ & 0.30 \\
\hline & 30 & 30 & 2.1 & 1.8 & 5.1 & $\begin{array}{c}0.000 \\
2\end{array}$ & 0.171 \\
\hline \multirow{3}{*}{$\begin{array}{l}\text { Paralle } \\
\text { l } \\
\text { rectan } \\
\text { gles } \\
(2: 1)\end{array}$} & 10 & 5 & 3.1 & 2.5 & 7.2 & $\begin{array}{c}0.000 \\
4\end{array}$ & 0.26 \\
\hline & 20 & 10 & 1.5 & 1.1 & 3.2 & $\begin{array}{c}0.000 \\
3\end{array}$ & 0.13 \\
\hline & 30 & 15 & $\begin{array}{c}1.0 \\
2\end{array}$ & 0.889 & 2.4 & $\begin{array}{c}0.000 \\
1\end{array}$ & 0.06 \\
\hline $\begin{array}{l}\text { Paralle } \\
\text { l } \\
\text { rectan } \\
\text { gles } \\
(3: 1)\end{array}$ & 30 & 10 & $\begin{array}{c}0.6 \\
78\end{array}$ & 0.43 & 1.5 & $\begin{array}{c}0.000 \\
09\end{array}$ & 0.08 \\
\hline
\end{tabular}

\section{RESULTS AND DISCUSSION}

The mass and stiffens of a structure affect its natural frequency value.Lighter structures and machines are known to have higher natural frequencies [19]. It is well acknowledged in the literature that shorter buildings tend to be less flexible and have higher natural frequencies compared to taller buildings. Further investigation of natural frequencies and impacts on other associated characteristics of structures are of need to further investigations. We have demonstrated in this paper that the natural frequency of a structure of a given height can be moderated by means of controlling the ratio of height to its base area.

An analysis of the structures' performance with optimisation of structures' natural frequencies with variations of these parameters are performed and presented using fuzzy logic control system. The results show that whilst the height of a structure is recognised as the most effective variable that could affect its natural frequency, results from the analysis also show that base area and ratio of height/area of a structure also affect its natural frequency value. These results are likely to have implications on many engineering applications includingstructures, buildings and machine design. Implications for the design of buildings and structures in addition to specifications for composite materials may also benefit from this innovative research.

With the finding that wood has a relatively high natural frequency compared to that of concrete and steel, this has highlighted an interesting area that is requiring further research and investigation. Areas in which this may have an important part to play include reinforcing material complementing steel and concrete, which may play a role in research for earthquake resistance and wood products.

\section{CONCLUSIONS AND RECOMMENDATIONS}

Natural frequencies of buildings and structures depend on the knowledge of materials and their natural characteristics. The five most used materials that are used for general structures and buildings are steel, concrete, wood, plastic and aluminum. Concrete is the most common material in buildings, steel is the most common material used in structures and heavy machinery and wood is most commonly used in many aspects of domestic construction, fencing in addition to commercial use. Assessing vibration and natural frequencies of these materials is critical in ensuring the most cost-effective approach and safety to engineering designs.

In this research, we present data highlighting that the height of buildings and structures is still the most prevailing factor affecting their natural frequencies. However, the ratio of height/area also shows relevance in affecting the structure natural frequency. The type of material used represented by its density and the module of elasticity seem to have significant impact on the natural frequency. Our results show that wood has the highest natural frequency amongst the five selected materials, followed by steel then concrete. Implications from this investigation will be useful for heavy machinery and building structures. 


\section{ACKNOWLEDGMENT}

This research was funded by the Deanship of Scientific Research at Princess Nourahbint Abdulrahman University through the Fast-track Research Funding Program. The work reported in this article has been conducted while the researchers are affiliated with Princess Nourahbint Abdulrahman University.

\section{REFERENCES}

1. Acunzo G, Fiorini N, Mori F, Spina D (2018) Modal mass estimation from ambient vibrations measurement: A method for civil buildings. Mechanical Systems and Signal. Elsevier.

2. Ansari A., (1998) The Basics of Fuzzy Logic: A Tutorial Review, Computer Education, Stafford - Computer Education Group, U.K. 88:5-9.

3. Askarzadeh A (2016) A novel metaheuristic method for solving constrained engineering optimization problems: Crow search algorithm. Computers and Structures. Volume 169, Pages 1-12.

4. Carrillo J and Alcocer SM (2013) "Simplified Equation for Estimating Periods of Vibration of Concrete Wall Housing". Engineering Structures, vol. 52, pp. 446-455, DOI: 10.1016/j.engstruct.2013.03.011.

5. Chopra AK (2011) Dynamics of Structures: Theory and Applications to Earthquake Engineering, Prentice Hall, United States.

6. Chopra AK and Goel, R.K. (2000) "Building periodformulas for estimating seismic displacements." Earthquake Spectra, vol. 16, no. 2, pp. 533-536, DOI: http:// dx.doi.org/10.1193/1.1586125.

7. Davenport A, James L and Silverleaf A (1971) The response of six building shapes to turbulent wind. 269 Philosophical Transactions of the Royal Society of London. Series A, Mathematical and Physical Sciences http://doi.org/10.1098/rsta.1971.0039

8. Ebrahimpoura A and Sackb R (2005) A review of vibration serviceability criteria for floor structures. Computers \& Structures. Volume 83, Issues 28-30, Pages 2488-2494.

9. FL Zhang, CE Ventura, HB Xiong, WS Lu (2018) Evaluation of the dynamic characteristics of a super tall building using data from ambient vibration and shake table tests by a Bayesian approach Control and Health. Wiley Online Library

10. Fu J, Zheng Q, Huang Y, Wu J, Pi Y, Liu Q (2018) Design optimization on high-rise buildings considering occupant comfort reliability and joint distribution of wind speed and direction. Engineering Structures, Elsevier.

11. Fuzzy control programming (1977). Technical report, International Electrotechnical Commission, (1997).

12. Gholami R, Shirgir V, Ghanbari A (2018) A New Analytical Model for Estimating the Natural Frequency of Pile-Supported BridgesTransportation, Springer.

13. KT Park, M Torbol, S Kim (2018) Vision-based natural frequency identification using laser speckle imaging and parallel computing Computer-Aided Civil . Wiley Online Library.

14. Johnson, L (2019). "How to Calculate Natural Frequency" sciencing.com, https://sciencing.com/calculate-natural-frequency5171316.html.

15. Manigandan S, Gunasekar P, Devipriya J (2018) Energy-saving potential by changing window position and size in an isolated building. Journal of Ambient. Taylor \& Francis.

16. Mendel J (1995) Fuzzy logic systems for engineering: a tutorial. Proceedings of the IEEE, 83(3):345-377.

17. Tomassetti G, Barboni R, Benedetti M (2005) Optimisation methodology for cryotanks. Computers \& Structures. Volume 83, Issues 28-30. Pages 2293-2305.

18. Vlachos IK and Sergiadis GD (2007) "Intuitionistic fuzzy information-applications to pattern recognition". Pattern Recognition Letters. 28(2): 197-206. doi:10.1016/j.patrec.2006.07.004.

19. Preumont A. (1997) Analysis and synthesis in the frequency domain. In: Vibration Control of Active Structures. Solid Mechanics and Its Applications, vol 50. Springer, Dordrecht

20. Yaghoobi M, Mazaheri S and Jabbari E (2012) Determining Natural Frequency of Free Spanning Offshore Pipelines by Considering the Seabed Soil Characteristics, Journal of the Persian Gulf, vol.3, No. 8 , pp: 25-34.

21. Zadeh L A (1965) Fuzzy Sets. Information \& Control. 8, 338-353.

\section{AUTHORS PROFILE}

Maha M. A. Lashin, Egyptian, mmlashin@pnu.edu.sa. Associated Professor Degree in mechanical design and production. Ph.D. degree in Artificial Intelligent from Cairo university-Egypt, Assoc. Prof. at PNU, College of Engineering, Kingdom of Saudi Arabia. Supervision of Master and Philosophy Doctor Degrees for Students of Engineering Colleges for example, Smart Memory Alloy Development for the Effective Use of Control Systems, Diagnosis of Machinery Malfunctions by Analyzing the Vibrations Using Genetic Algorithms, Modeling and simulation of the Static and Dynamic Performance of Sandwich Beams, Automated Monitoring and Measuring Improvement of Production System Performance and Control of Air Handling Unit as a Method of Reducing Power Consuming. Published more than 30 papers in international journals at fields of Automatic Control, Mechanical Vibration Analysis, Artificial Intelligent and Composite Materials.

Wafaa Shoukry Saleh, is a Professor of Transport Engineering at Edinburgh Napier University (UK), w.saleh@napier.ac.uk,and a Chartered Engineer with over 30 years' experience in teaching, research and practice in the UK. Currently, Wafaa is a visiting Professor at PNU in Riyadh (KSA).w.saleh@napier.ac.uk, The focus of her research interests include modelling travel behaviour, accident analysis and investigations, transport and the environment, travel demand management, traffic engineering and travel behaviour. Wafaa has successfully directed many $\mathrm{PhD} / \mathrm{MPhi}$ completions and published over 50 refereed articles and has edited several books and Special Issues at top academic international transport Journals. Wafaa is applying her working knowledge of theory and practice which is reflected in various publications and academic work.

Fadwa Alrowais, is an Assistant Professor with a degree incomputer science from Faculty of Electronics and Computer Sciences at Southampton University in the (UK), fmalrowais@Pnu.edu.sa. Her current academic work and research include Designing Arabic applications and frameworks for Dyslexia Training Tools, designing new frameworks of general dyslexia and Arabic dyslexia elementsand for evaluating Arabic Dyslexia Technology Training Tools. Interest and published papers include in ICT fields.She is a Member in Saudi Computers Society in Riyadh, Saudi Arabia and a Member in the Alumni Society in University of Southampton, UK until 2020. 